\title{
Os Direitos e as Obrigações do Titular do Capital Social da Empresa Individual de Responsabilidade Limitada (EIRELI) ${ }^{1}$
}

\section{The Rights and Obligations of Registered Capital Holder of Individual Limited Liability Enterprise (EIRELI)}

\author{
Fábio Pugliesi \\ Daniel Mayerle \\ Andrey Ricardo Machado
}

\begin{abstract}
Resumo: Este artigo estuda os direitos e as obrigações do titular do capital social da Empresa Individual de Responsabilidade Limitada (EIRELI). Inicialmente analisam-se os estudos antecedentes, o processo legislativo e os preceitos relativos à EIRELI. Examinam-se, posteriormente, os direitos e as obrigações dos sócios da sociedade limitada. Em seguida, analisam-se as características da pessoa jurídica na EIRELI, os requisitos para ser titular do capital social da EIRELI, a regra determinante do capital social mínimo e destacam-se os dispositivos da sociedade limitada aplicáveis à EIRELI. Por fim, considera-se que por ter a Lei n. 12.441, de 11 de julho de 2012, estabelecido uma nova espécie de pessoa jurídica, os direitos e obrigações do titular do capital social devem atender à função social da instituição.
\end{abstract}

Palavras-chave: EIRELI. Pessoa Jurídica. Empresário Individual.

\begin{abstract}
This paper analyzes the rights and obligations of the holder of the capital of the Individual Limited Liability Enterprise (EIRELI). It analyzes previous studies, the legislative process and the rules concerning EIRELI. The rights and obligations of the partners of a limited liability enterprise are examined later. Then we analyze the characteristics of the legal entity in EIRELI, the requirements to hold the capital of EIRELI, the rule determining the minimum capital and stand out devices applicable to the EIRELI. Finally, it is considered that because the Law n. 12.441, of 11 July 2012, established a new kind of entity, the rights and obligations of the holder of the capital must meet the social function of the institution.
\end{abstract}

Keywords: EIRELI. Entity. Individual Entrepreneur.

${ }^{1}$ Recebido em: 12/12/2012.

Revisado em: 26/02/2013.

Aprovado em: 12/03/2013. 


\section{Introdução}

A Empresa Individual de Responsabilidade Limitada (EIRELI), instituída pela Lei n. 12.441, de 11 de julho de 2011, que entrou em vigor em 8 de janeiro de 2012, constitui a mais recente espécie de pessoa jurídica no Direito brasileiro a ser analisada no presente trabalho².

Ocorre, porém, que se tem procurado identificar na EIRELI uma proximidade com o empresário individual, embora as normas que disciplinam tal pessoa jurídica prevejam a aplicação subsidiária da sociedade limitada.

Independentemente da alusão a "empresário individual”, contida na expressão que identifica a EIRELI e a aplicação subsidiária da disciplina da sociedade limitada, em vista de se tratar de uma pessoa jurídica, há de se precisar as características e as funções que lhe são próprias, a exemplo do que se faz com as demais espécies de pessoa jurídica.

Relativamente, ao titular do capital social da EIRELI, cabe determinar seus direitos e suas obrigações.

Constituindo um reflexo da aceitação da EIRELI, o Ministério da Ciência, Tecnologia e Inovação, por meio da Secretaria de Desenvolvimento Tecnológico e Inovação, e o Conselho Científico e Tecnológico (CNPq), como se verifica na Chamada Pública MCTI/SETEC/CNPq n. 17/12 - RHAE Pesquisador na Empresa, passaram a exigir que a pessoa jurídica seja instituída sob a forma de EIRELI para o recebimento de apoio financeiro nos projetos relativos à inserção de mestres e doutores em seus projetos.

Inicialmente, analisam-se os estudos anteriores ao debate legislativo que culminou na adoção da Empresa Individual de Responsabilidade Limitada (EIRELI).

Posteriormente, analisa-se a disciplina dos direitos e das obrigações do sócio na sociedade limitada aplicáveis ao tema.

\footnotetext{
2 Resultado do projeto de Pesquisa apoiado por bolsa de iniciação científica FAPEPIBIC-UNIDAVI, mantido pelo Centro Universitário para o Desenvolvimento do Alto Vale do Itajaí (UNIDAVI).
} 
Por fim, identificam-se os direitos e as obrigações do titular do capital social da EIRELI.

\section{Empresa Individual de Responsabilidade Limitada (EIRELI)}

Nesta etapa serão analisados o debate legislativo que culminou na adoção da Empresa Individual de Responsabilidade Limitada (EIRELI) e suas características consideradas mais relevantes para os fins deste artigo e serão examinados os estudos que antecederam a sua instituição.

Ao longo do século XX, no Brasil, experimenta-se que o interesse social deva ser atendido de melhor forma com a conservação da atividade empresarial na hipótese de exclusão de sócio que leve a permanência de um só no quadro social. Nesse sentido, tem-se o estudo de Rubens Requião no qual defende a preservação da sociedade comercial, na hipótese de exclusão do sócio, constitui uma iniciativa inédita. (REQUIÃO, 1959)

Sylvio Marcondes Machado, autor da parte de Direito da Empresa do Código Civil, chegou a defender um patrimônio de afetação para o comerciante individual (MACHADO, 1956), constituindo uma iniciativa para preservar o patrimônio individual em caso de insucesso na iniciativa empreendedora e, indiretamente, um estímulo a esta.

Observa-se que, à época dos estudos de Rubens Requião e Sylvio Marcondes Machado, vigia a Lei n. 556, de 25 de junho de 1850 - Código Comercial, daí a denominação de comerciante àquele que exercia a mercancia como sua profissão, conforme o disposto no artigo 9 do Código Comercial.

A Lei n. 6.404, de 15 de dezembro de 1976, lei da sociedade por ações, instituiu em seu artigo 251 a subsidiária integral que tem como única acionista uma sociedade, instituída de acordo com as leis brasileiras. Abstrai-se a discussão da exigência da única acionista ser sociedade por ações ou enquadrar-se em qualquer outra espécie de sociedade empresarial, especialmente a limitada, em razão de extrapolar os limites deste artigo. 
Feitas essas referências iniciais, passa-se a analisar especificamente a EIRELI. A disciplina de EIRELI resulta do Projeto de Lei n. 4.605, de 4 de fevereiro de 2009, de autoria do Deputado Marcos Montes, observando que na "explicação de ementa" indica-se "também chamada sociedade unipessoal", referindo a exposição de motivos o artigo de Guilherme Duque Estrada de Moraes (2003) no projeto de lei.

Destaca este artigo que a constituição de grande parte das sociedades limitadas busca apenas limitar a responsabilidade do empresário ao valor do capital da empresa, denominando-se de "sociedade faz de conta".

A par da burocracia, esse modelo de "sociedade faz de conta" gera processos judiciais com sócios que possuem uma quantidade de cotas insignificantes na empresa.

Em 8 de abril de 2009, apensou-se ao projeto de lei do Deputado Marcos Montes o projeto de lei do Deputado Eduardo Sciarra, com o mesmo objetivo e que apresenta razões semelhantes, destacando-se que esse projeto de lei propôs a denominação de "empreendimento individual de responsabilidade limitada" e a abreviatura "EIRL", substituída após por EIRELI pela dificuldade da pronúncia. Aprovado pela Câmara dos Deputados e pelo Senado Federal, remeteu-se a lei para a sanção da Presidência.

O pano de fundo de tais discussões foi facilitar e estimular o acesso ao mercado, a livre iniciativa, bem como simplificar a liberdade de contratar por meio do controle concentrado da pessoa jurídica em uma pessoa natural.

A Presidente sancionou a lei, todavia vetou o parágrafo 4, em virtude da proposta do Ministro do Trabalho e Emprego, que considerou nele contido o limitativo da aplicação da desconsideração da pessoa jurídica, o que será objeto de análise posterior no presente trabalho. Reproduz-se, desde já, o dispositivo vetado, uma vez que pode orientar o entendimento posterior sobre a matéria ante a recente edição da lei:

$\S 4^{\circ}$ Somente o patrimônio social da empresa responderá pelas dívidas da empresa individual de responsabilidade limitada, não se 
confundindo em qualquer situação com o patrimônio da pessoa natural que a constitui, conforme descrito em sua declaração anual de bens entregue ao órgão competente.

Expõem-se a seguir as características da EIRELI, realçando os aspectos relevantes para este trabalho.

A EIRELI deve ser constituída por uma única pessoa que deve ser, também, titular da totalidade do capital social, devidamente integralizado, não podendo ser este inferior a 100 (cem) vezes o maior salário-mínimo vigente no País.

O nome empresarial, que pode ser uma firma ou denominação (nesta designando o objeto da atividade empresarial), constará obrigatoriamente, ao final, a abreviatura "EIRELI", bem como o regime jurídico da sociedade limitada aplica-se, no que couber, subsidiariamente à EIRELI.

O titular do capital social que constituir a EIRELI não pode participar de outra empresa dessa modalidade, conforme o artigo 980-A, parágrafo segundo do Código Civil, logo há de constar a declaração no ato constitutivo referindo a não participação em outra EIRELI.

Ademais, a EIRELI pode decorrer da concentração das cotas, em um único sócio, assim se admitiu a possibilidade de se converter, por exemplo, uma sociedade limitada em EIRELI.

Ocorrido isso há de se proceder à adaptação do ato constitutivo à lei da EIRELI e levar ao registro público competente.

O caput do artigo 980-A do Código Civil faz alusão à “pessoa" sem distinguir entre pessoa natural ou jurídica, todavia o parágrafo segundo desse artigo refere-se à pessoa natural ao dispor que "poderá figurar em uma única empresa desta modalidade".

Assim surge a interpretação de que uma pessoa jurídica estaria autorizada a instituir uma EIRELI, ainda mais que a uma sociedade limitada se entende estar vedada a constituição da subsidiária integral, autorizando-se isso exclusivamente à sociedade por ações, em razão de sua disciplina encontrar-se na lei especial da sociedade por ações já mencionada. (SERSON, 2012, p. 146-151) 
Embora o entendimento possa apresentar fundamento, salienta-se a incompatibilidade com o regime jurídico da EIRELI já exposto e verifica-se no fato do legislador ter optado pela criação de uma nova espécie de pessoa jurídica ligada à figura da pessoa natural, portanto, empresário individual. Assim, dentro dos limites do presente trabalho, analisar-se-ão os direitos e as obrigações do titular do capital social da EIRELI nessa perspectiva.

Afinal, admite-se à EIRELI a aptidão de ser microempresa ou empresa de pequeno porte, disciplinadas na Lei Complementar n. 123, de 14 de dezembro de 2006, que institui o Estatuto da Microempresa e Empresa de Pequeno Porte, com a redação que foi dada pela Lei Complementar n. 139, de 10 de novembro de 2011.

Aliás, o estatuto mencionado exclui do regime de microempresa e empresa de pequeno porte as sociedades que tenham como sócios as pessoas jurídicas, consoante o disposto no artigo $3^{\circ}$, parágrafo quarto, inciso I deste, que se aplica por analogia às EIRELIs.

O parágrafo quinto do artigo $5^{\circ}$ do artigo 980-A do Código Civil preceitua que poderá ser atribuída à empresa individual de responsabilidade limitada, constituída para a prestação de serviços de qualquer natureza a remuneração decorrente da cessão de direitos patrimoniais de autor ou de imagem, nome, marca ou voz de que seja detentor o titular da pessoa jurídica, vinculados à atividade profissional. Diante da controvérsia suscitada, esse dispositivo será analisado na parte em que se tratará dos direitos e das obrigações do titular do capital social da EIRELI.

Enfim, resulta em uma forma jurídica que busca realizar o disposto na Constituição da República Federativa do Brasil (CRFB), em seu inciso IX do artigo 170 (FACCHIM, 2010), bem como o artigo 179 da Constituição da República Federativa do Brasil (CRFB). Tais dispositivos elencam, entre os princípios que devem orientar a ordem economia, a economia brasileira e o tratamento favorecido para as empresas de pequeno porte, que autoriza a reivindicação de tais empresas por políticas públicas neste sentido. (GRAU, 2007) 
Diferentemente das sociedades, o tratamento distinto entre as EIRELIs caracterizadas como microempresas ou empresas de pequeno porte e as que, eventualmente, não se enquadrem no Estatuto da Microempresa e Empresa de pequeno porte, como as que se refiram à atividade relativa ao profissional liberal, leva a situações iníquas. Isso decorre do fato de que, por trás da novel espécie de pessoa jurídica, deve estar sempre uma pessoa natural, e a CRFB não autoriza tal discriminação que, em última instância, dar-se-á entre pessoas naturais titulares do capital social da EIRELI.

\section{Direitos e Obrigações do Sócio na Sociedade Limitada}

A seguir analisa-se a disciplina dos direitos e das obrigações do sócio na sociedade limitada, considerando as disposições relevantes para a EIRELI, o histórico dela e o regime jurídico de sua administração.

Define-se a sociedade limitada como a espécie de sociedade em que a responsabilidade de cada sócio restringe-se ao valor de suas cotas, respondendo todos pela integralização do capital social (BRASIL, 2002), consoante a dicção do artigo 1.052 do Código Civil.

A sociedade limitada foi introduzida no direito brasileiro pelo Decreto n. 3.708, de 10 de janeiro de 1919, tendo o Código Civil revogado este inteiramente. Dentre as disposições revogadas encontra-se a que exigia que a administração somente poderia ser exercida pelo sócio, então denominado "sócio-gerente" e ainda aceita na linguagem coloquial.

A experiência jurídica demonstra ser a sociedade limitada mais difundida de exercício da livre iniciativa admitindo-se, porém, distribuições de capital e controle que relativizam o espírito de coordenação de esforços entre os sócios.

Isso traz dificuldades para efetivar as regras a seguir elencadas, tendo reflexos no Direito Consumidor, no Direito da Concorrência, no Direito do Trabalho e no Direito Tributário, o que, dados os limites do presente trabalho, não se revela possível se deter nesses aspectos. 
Como o empresário individual, a sociedade limitada deve inscrever-se no Registro das empresas mercantis antes de iniciar suas atividades (BRASIL, 2002, art. 967), quando empresárias, bem como no registro civil das pessoas jurídicas, quando tiver objeto próprio das sociedades simples.

Constituem deveres dos sócios integralizar suas cotas e agir com lealdade à sociedade. Os direitos desses sócios são a participação nos lucros sociais e a fiscalização dos negócios da sociedade, considerando nula a cláusula que exclua algum sócio da participação dos lucros sociais. (BRASIL, 2002, art. 1.008)

Decorre do dever do membro da sociedade agir com lealdade em relação a esta, a regra que determina ao sócio que, no exercício da função do administrador e sem consentimento escrito dos outros sócios, aplicar créditos ou bens sociais em proveito próprio, ou de terceiros. Caso contrarie isto deverá restituir os créditos ou bens sociais à sociedade, ou pagar o equivalente, com todos os lucros resultantes, devendo responder pelo prejuízo que, eventualmente, resultar de sua conduta. (BRASIL, 2002, art. 1.017)

$\mathrm{Na}$ hipótese de cessão de cotas sem a correspondente modificação do contrato social com o consentimento dos demais sócios, não terá eficácia quanto aos sócios e à sociedade, acarretando a responsabilidade solidária do cedente e do cessionário por dois anos. (BRASIL, 2002, art. $1.003)$

Entende, porém, José Edwaldo Borba que o mesmo efeito poderá ser obtido mediante um termo de cessão de cotas, assinado apenas pelo cedente e pelo cessionário, devendo ser registrado no registro competente. (BORBA, 2003, p. 62)

$\mathrm{Na}$ sociedade simples que se aplica secundariamente à sociedade limitada na EIRELI, a administração cabe aos sócios. Todavia, diversamente na limitada, estranhos à sociedade limitada podem exercer a administração, desde que permita o contrato social (BORBA, 2003, p. 20). Deve dar-se a designação do administrador por unanimidade, quando o capital não estiver integralizado, e por três quartos quando tiver ocorri- 
do a integralização. Justifica isso Sylvio Marcondes Machado, autor do dispositivo, pois, caso não tenha havido o aporte integral dos recursos, todos respondem pela parte não integralizada do capital. (MARCONDES, 1977 , p. 20)

Impõe-se, de qualquer forma, ao que exerce a função do administrador, sócio ou não, a obrigação de responder por perdas e danos perante a sociedade e terceiro que, em síntese, veicula um corolário da determinação de agir com o cuidado e diligência que todo homem ativo e probo costuma empregar na administração de seus próprios negócios. (BRASIL, 2002, art. 1.020-1.027)

Responde, também, por perdas e danos perante a sociedade e terceiros o sócio que, tendo em alguma operação interesse contrário ao da sociedade, participar da deliberação que a aprove graças a seu voto. (BRASIL, 2002, art. 1.010, $\S 3^{\circ}$ )

Destaca-se que responde, igualmente, por perdas e danos o sócio na função de administrador ao realizar operações tanto de gestão quanto nas operações relativas a bens e a serviços sabendo, ou devendo saber, que estava agindo em desacordo com a maioria. (BRASIL, 2002, art. 1.014)

O sócio admitido em sociedade já constituída não se exime das dividas sociais anteriores à sua admissão. (BRASIL, 2002, art. 1.025)

A execução do credor particular do sócio sem bens suficientes pode fazer recair a execução sobre o que a ele couber nos lucros da sociedade ou na parte que lhe tocar em liquidação. (BRASIL, 2002, art. 1.026)

$\mathrm{O}$ rigor na gestão e da participação societária tem aumentado na medida em que se tem conferido maior eficácia às disposições referentes à responsabilidade dos sócios nas deliberações que impliquem no descumprimento das obrigações tributárias, bem como a inobservância da legislação trabalhista.

É irrelevante que o sócio exerça a função de fato de administrador sem os regulares atos societários que o autorizem, respondendo, ainda, com maior razão pelas perdas e pelos danos que causar à sociedade e a terceiros, importando o controle que tenha na atividade societária e não somente a quantidade de cotas que lhe pertençam. 
Feitas essas considerações, relativas aos direitos e às obrigações dos sócios da sociedade limitada, examinam-se, a seguir, os direitos e as obrigações do sócio na EIRELI.

\section{Direitos e Obrigações do Titular do Capital da Empresa Indi- vidual de Responsabilidade Limitada}

Analisam-se a seguir os direitos e as obrigações do titular do capital social da EIRELI, bem como se indicam as disposições concernentes à sociedade limitada, aplicáveis àquela.

Deve-se, antes de tudo, ponderar que o ordenamento jurídico, a par das relações de subordinação das normas, é governado por relações de coordenação entre elas, observado que, em relação às demais, uma nova prescrição normativa altera todo o sistema. (LUMIA, 2003, p. 67)

Pode-se dizer que a discussão sobre a essência da pessoa jurídica ficou ultrapassada em razão do seu sucesso, tão disseminado é o instituto e tão diferentes as formas que assume que se tornou um autêntico pressuposto no Direito.

José Edwaldo Tavares Borba identifica uma controvérsia entre os estudiosos que se filiam à vertente "contratualista" e outros à "anticontratualista" ou "institucionalista" da sociedade. (BORBA, 2003, p. 19-20)

$\mathrm{O}$ institucionalista considera que o interesse social não se reduz ao dos sócios, mas ao interesse de continuidade da sociedade, enquanto os seguidores da corrente antípoda focam sua análise no interesse dos sócios.

Tullio Ascarelli, não obstante se possa classificar na corrente contratualista, assinala sinteticamente que, ante a inexistência da pluralidade de sócios, deve-se falar em pessoa jurídica e patrimônio autônomo, colocando a questão em termos diferentes ao destacar as características que são próprias às relações entre os sócios em cada pessoa jurídica. (ASCARELLI, 1969, p. 290-292)

Assim, segundo o propugnado por esse autor, ainda que tenha escrito anteriormente ao surgimento da EIRELI, reitere-se em outros termos, a pessoa jurídica deve ser analisada na sua especificidade. 
Observa-se que o foco deste trabalho reside no Direito Empresarial, reconhecendo que os reflexos devem alcançar, por exemplo, o Direito Tributário, em virtude da prescrição do Código Tributário Nacional que, embora os institutos de direito privado, orientam a interpretação das normas tributárias. (BRASIL, 1966)

Em continuação, Calixto Salomão afirma que o Direito Empresarial requer, na interpretação dos textos normativos compreendidos em seu âmbito, a experiência particular à atividade regulada e os imperativos de ordem econômica (SALOMÃO, 2002, p. 153), não se limitando à analogia.

Contudo seja disseminada a utilização do termo "analogia", revela-se útil reproduzir, para os fins deste trabalho, a rigorosa definição de Giuseppe Lumia (2003, p. 91):

O recurso à analogia (ou argumentum a simili) ocorre quando uma norma jurídica que regula um determinado caso é aplicada a um caso diverso, mas congruente; isto é, uma dada norma aplica-se aos casos não previstos por ela desde que apresentem a mesma ratio do caso referente à norma.

Como se sabe, no Direito Empresarial, a própria validade da proposição normativa deve considerar as necessidades da economia.

Assim revelam-se úteis os ensinamentos de Max Weber, em seu livro "O Direito na Economia e na Sociedade" (WEBER, 2011), ao distinguir direito e convenção, observado que o uso decorre de um comportamento que abstrai a causa e o objetivo, o que se revela útil em uma instância da vida que contribui decisivamente para o sistema capitalista.

Como acentua esse autor, a convenção é um costume aprovado como válido e sujeito a uma reprovação moral, como a comunidade de empresários, diferenciando do direito pela falta de um staff disposto a usar a coação (WEBER, 2011, p. 16). Em vista disso, prossegue Weber afirmando, que a teoria econômica, portanto, chega a desconsiderar se norma se refere à convenção ou ao Direito, o que importa, por exemplo, é que "[...] o fato de possuir algo simplesmente quer dizer que ele pode 
confiar que outras pessoas não irão interferir com a disposição deste objeto". (WEBER, 2011, p. 42)

Dessa forma, a prática dos negócios pode chegar a rejeitar uma formulação formalmente coerente com o ordenamento ou adota que não afete o funcionamento da atividade econômica, daí a necessidade de considerar-se a peculiaridade da atividade empresarial nas formulações jurídicas como referido.

Tais fenômenos da atividade econômica devem guardar, porém, relação com os princípios orientadores da economia no Brasil, constantes na CRFB, em razão do dever da ordem econômica estar fundada na valorização do trabalho humano e na livre iniciativa, tendo por fim assegurar a todos existência digna, conforme os ditames da justiça social.

Com efeito, o tema suscita polêmica ao se tentar enquadrar a EIRELI como uma sociedade com um sócio apenas ou com um empresário individual, "transformado" em pessoa jurídica em que a responsabilidade da pessoa natural limita-se ao capital social atribuído a ela se, na interpretação do ordenamento, busca-se entender o significado isolado de cada palavra que serve para denominar a nova espécie de pessoa jurídica, EIRELI.

Assim, a par da verificação das regras, relacionadas à EIRELI, que disciplinam a sociedade limitada devem ser conhecidas as necessidades econômicas a serem atendidas.

Reputam-se úteis, levar em conta, as ideias de Hans Kelsen para avaliar os direitos e obrigações do titular do capital social da EIRELI.

Segundo Kelsen, a pessoa é o complexo de deveres, observado que o direito é um reflexo do dever imposto a um ou a grupo de indivíduos (KELSEN, 1984, p. 185). Afinal, neste autor, pessoa é uma criação do Direito, tanto natural quanto jurídica, "[...] outras entidades, tais como certas comunidades como as associações, as sociedades por ações, os municípios, os Estados". (COMPARATO, 1983, p. 241)

Assim, no autor mencionado, por trás da pessoa jurídica sempre se encontram indivíduos, um conjunto deles ou, no caso da EIRELI, apenas um. 
Aliás, alerta Fabio Konder Comparato que a personalização é uma técnica jurídica que atende às necessidades de um patrimônio autônomo, do qual ativo e passivo não se confundem com os direitos e as obrigações dos sócios, bem como a limitação ou supressão de responsabilidades individuais. (COMPARATO, 1983, p. 280-281)

Observe que, segundo o autor, essa separação patrimonial implica gradações, sendo mais pronunciada nas sociedades anônimas e menos nas demais. (COMPARATO, 1983, p. 281)

Assim, é possível afirmar que a expressão "responsabilidade limitada" pode implicar direitos e deveres diversos, dependendo da pessoa jurídica a que se refere.

A título de exemplo, pode-se mencionar a expressão "sociedade de economia mista", que comporta conceitos legais diversos ante as diferentes atividades desenvolvidas pela pessoa jurídica, como estuda Eros Roberto Grau (1988, p. 87). Para esse autor, perspectiva que se adota para os fins do presente trabalho, os conceitos jurídicos devem ser aplicados ante a "consideração dos fins para os quais serão usados".

Assim, como adverte Calixto Salomão, há de ser posta de lado a contraposição entre patrimônio separado e personalidade jurídica, uma vez que aquela nada diz, por si só, em vista do regime de responsabilidade de cada pessoa jurídica. (SALOMÃO, 2003, p. 163)

Ainda que esse autor parta de pressuposto diverso de Carlos Henrique Abrão, compatibilizam-se os entendimentos, pois a empresa individual de responsabilidade limitada exige para sua criação, afinal, um patrimônio peculiar, aplicando-se a exigência de um capital social mínimo para limitar a responsabilidade do titular do capital social. (ABRÃO, 2012, p. 30)

Autoriza-se que, em decorrência da reunião das cotas na pessoa de um dos sócios, passe a sociedade a se tornar uma EIRELI. Impõe, porém, um capital mínimo integralizado de cem salários-mínimos, observe-se integralizado e não subscrito. 
A subscrição, como se sabe, significa a assunção da obrigação de integralizar as cotas, o que se revela insuficiente para a constituição da EIRELI.

Segundo Carlos Henrique Abrão, se a EIRELI não tiver o capital social mínimo exigido, passa o titular do capital social a responder, de imediato, pelas obrigações da pessoa jurídica em tela (ABRÃO, 2012, p. 20). Observado que, na hipótese, de serem conferidos bens na formação do capital social que não correspondam a esse valor, passa igualmente o titular do capital a responder pelas obrigações.

Como assinala Carlos Henrique Abrão, a referência à empresa individual criou um patrimônio de afetação, aplicando-se a exigência de um capital social mínimo para limitar a responsabilidade do titular do capital social. (ABRÃO, 2012, p. 31)

Lamenta esse autor que melhor teria disposto o legislador que, por exemplo, após um período de tempo e, havendo uma perda por hipótese de $20 \%$ do salário mínimo, estaria o empresário obrigado a fazer o aumento de capital.

Por certo a lei da EIRELI admite a existência de prejuízos, todavia se entende que tal exigência condena a prática, disseminada no ambiente empresarial brasileiro, da pessoa jurídica, em especial a sociedade limitada, ter prejuízos indefinidamente e formar um "patrimônio líquido negativo".

Nesse caso, se uma EIRELI vende fogos de artifício e seu estabelecimento resta destruído por um incêndio, responde o titular do capital pelo prejuízo causado aos credores, quando sequer celebrou um contrato de seguro para cobrir as perdas e danos causados.

Dessa forma, reitere-se, a manutenção do capital social durante a realização do objeto social, a par da necessidade da observância do limite referido, salvo casos fortuitos que justifiquem sua diminuição, constitui um requisito para a manutenção da limitação de responsabilidade do titular do capital social da EIRELI. 
Ademais, o titular do capital social da EIRELI exerce tal soberania, nesta espécie de pessoa jurídica, que se lhe impõem direitos e obrigações próprios, a par dos atribuídos aos sócios da limitada.

Facilita-se, como já destacado, a identificação da responsabilidade da pessoa natural pelos fatos que culminam na desconsideração de pessoa jurídica, uma vez que nas sociedades o controle não se confunde com a titularidade da maioria das cotas do capital social, a exemplo do verificado nas sociedades anônimas. (COMPARATO, 1983, p. 150)

O artigo 981 do Código Civil dispõe que celebram contrato de sociedade as pessoas que reciprocamente se obrigam a contribuir, com bens e serviços, para o exercício de atividade econômica e a partilha, entre si, dos resultados. Todavia, a experiência mostra que, muitas vezes, o caráter societário inexiste devendo aquele que possui ínfimo ou até desprezível participação suportar as decisões do detentor do controle societário.

Ainda assim, aplica-se a disciplina na sociedade limitada subsidiariamente à EIRELI, desse modo devem ser identificadas normas que sejam compatíveis com a pessoa jurídica em tela.

A título de exemplo o disposto no artigo 997 do Código Civil, relativo à sociedade simples cujos preceitos aplicam-se subsidiariamente à sociedade limitada que, por sua vez, aplicam-se à EIRELI as obrigações do titular do capital social inicia quando se requer a inscrição da pessoa jurídica (EIRELI) perante o registro público.

O registro pode ser civil ou comercial, por efeito do artigo 983 do Código Civil, uma vez que a sociedade limitada pode ter como objeto a atividade empresarial próprio de sociedade simples.

Não se afiguram suficientes os argumentos que defendem que EIRELI não pode ter atividade própria da sociedade simples.

O fato de constar na sua denominação o termo "empresário" e a alusão no parágrafo segundo ao termo "empresa", repita-se, revela-se insuficiente para destiná-la exclusivamente à atividade própria de empresário, segundo a terminologia do Código Civil, dada a importância da prática dos negócios na área jurídica objeto de consideração. 
Confirma esse entendimento a dicção do parágrafo quinto do artigo 980-A do Código Civil que autoriza a atribuição à EIRELI, constituída para a prestação de serviços de qualquer natureza, a remuneração decorrente da cessão de direitos patrimoniais de autor ou de imagem, nome, marca ou voz de que seja detentor o titular da pessoa jurídica, vinculados à atividade profissional.

Além disso, a diferenciação de empresário daqueles que exercem atividade científica ou artística atendeu a necessidades de meados do século XX.

Corrobora este entendimento, a justificação do autor da parte de Direito da Empresa no Código Civil, Sylvio Marcondes Machado. Entende por exclusão este autor, à época que elaborava o projeto do Código Civil em vigor, não ser empresário aquele que tem atividade "criadora" de bens e serviços, "[...] faltando aquele elemento de organização dos fatores de produção, ou a coordenação de fatores é meramente acidental”. (MARCONDES, 1977, p. 10-11)

Trata-se de asserção que, como é público e notório, não se coaduna com a necessidade histórica da segunda década do século XXI, uma vez que se oferecem até cursos de marketing para advogados e outros profissionais liberais, observado ser o marketing uma técnica própria da administração de empresas, verifica-se ademais a área de marketing para serviços profissionais já na década de 1980. (BLOOM; KOTLER, 1988)

A Instrução Normativa n. 117 do Departamento Nacional do Registro do Comércio indica que a EIRELI não pode exercer atividade de advocacia, considera-se que isso deva se aplicar às Juntas, quanto aos registros civis cabe ao Registro Civil das PJ de cada Estado, em razão da peculiaridade da advocacia, portanto restringindo a esta.

Essa disposição, que excepciona o advogado, guarda congruência com a decisão do Supremo Tribunal Federal na Ação Direta de Inconstitucionalidade (ADIN) n. 3.026-4 reconheceu a peculiaridade da Ordem Advogado do Brasil e, por consequência do advogado, das demais atividades relativas a serviços profissionais e científicos e os conselhos que, por ventura, representem e organizem a profissão. (BRASIL, 2005) 
Dessa forma, autoriza-se aos demais profissionais liberais a constituição e a atuação da EIRELI, salvo vedação expressa ao exercício de profissão por meio de EIRELI.

Logo se verifica estar diante de uma polêmica, quando se busca autorizar aos "não empresários" a constituição da EIRELI, que a tudo se assemelha à época da vigência do Código Comercial, digladiavam os entendimentos sobre se a atividade própria do comerciante ou não com base no conceito de "ato de comércio", considerando alguns taxativa a enumeração constante no artigo 19 do Regulamento n. 737 e, consequentemente, fora do regime comercial o que nela não era referido. (REQUIÃO, 2005, p. 41)

Outro aspecto que há de ser considerado decorre da hipótese de uma pessoa integralizar o capital de uma EIRELI deixando de manter um patrimônio suficiente para saldar seus débitos. Embora inexista uma sanção expressa no ordenamento, aplica-se, por analogia, a regra do artigo 1.026 do Código Civil já aludido, resultando em consequência que o credor particular do titular do capital social pode, na insuficiência de outros bens do devedor (titular do capital social), fazer recair a execução sobre o que a este couber nos lucros da sociedade, ou na parte que lhe tocar na liquidação que, no caso da EIRELI é a totalidade do patrimônio.

Além dessa disposição aplicam-se à EIRELI as seguintes disposições relativas às sociedades limitadas já analisadas.

O titular do capital social deve agir com lealdade em relação à EIRELI, sendo corolário disso, igualmente por analogia, a disposição que determina que, se aplicar creditos ou bens sociais em proveito próprio, ou de terceiros, terá de restituí-los à sociedade, ou pagar o equivalente, com todos os lucros resultantes, e, se houver prejuízo, por ele também responderá.

Tal regra torna-se muito mais eficaz na EIRELI do que, por exemplo, na sociedade limitada em decorrência da já assinalada facilitação na apuração de responsabilidade de que pode resultar a desconsideração da pessoa jurídica. 
A EIRELI pode ser administrada por terceiro, em razão da aplicação subsidiária da disciplina da sociedade limitada.

Dessa forma, o titular do capital social tem direito a fiscalizar a atividade da EIRELI, segundo os seus atos institutivos.

Na hipótese de cessão da titularidade do capital social, por ato societário, firmado pelo cedente e pelo cessionário. A responsabilidade do cedente, sem a correspondente modificação do ato societário que disciplina a EIRELI, não terá eficácia quanto a eles e à sociedade, acarretando a responsabilidade solidária do cedente e do cessionário por dois anos. (BRASIL, 2005, art. 1.003)

O titular do capital social de EIRELI constituída desde o início como tal ou resultante de sociedade já constituída não se exime das dívidas sociais anteriores à sua admissão. (BRASIL, 2005, art. 1.025)

Assim, ante o analisado, passa-se à conclusão do trabalho.

\section{Conclusões}

Inicialmente, forma analisados os estudos anteriores ao debate legislativo que culminou na adoção da Empresa Individual de Responsabilidade Limitada (EIRELI). Destacaram-se as características da EIRELI e a preocupação, por ocasião da sanção da lei que a instituiu, ao manter a aplicação da desconsideração da pessoa jurídica quando da sanção do texto aprovado no Congresso.

A relevância reside no fato de que, embora recente a espécie da pessoa jurídica no Código Civil, começa-se a exigir a instituição dessa espécie de pessoa jurídica para o Ministério da Ciência, Tecnologia e Inovação repassar recursos para o desenvolvimento de áreas estratégicas.

Dado o surgimento, ainda muito recente no momento da produção deste trabalho, deteve-se nos aspectos que buscaram identificar similitudes entre a EIRELI e as espécies societárias já existentes.

Investigaram-se os direitos e as obrigações do sócio na sociedade limitada, considerando as disposições relevantes para a EIRELI, o históri- 
co daquela, bem como as hipóteses em que o sócio ou o terceiro exerce a administração da sociedade.

Por fim, verificaram-se os direitos e as obrigações do titular das cotas da EIRELI na sua especificidade, com base nas peculiaridades que guardam cada uma das espécies de pessoa jurídica em relação às demais, inclusive as que exercem atividade econômica.

Afastaram-se, em consequência da perspectiva adotada aludida, os entendimentos que, em vista de conter a expressão "empresário individual", não se confunde com ele e nem com a sociedade limitada, cuja disciplina reforça a da EIRELI.

Assim, constatou-se estar superado, para fins de EIRELI, o óbice ao profissional artístico e científico de constituir, embora se imponha uma rigorosa observância da regra de um capital social mínimo de cem salários-mínimos por se entender ter ocorrido uma fraude à lei.

Ante o exposto, constatou-se aplicar à EIRELI, também, as normas da sociedade limitada relativas à necessidade da inclusão do objeto social ao se usar uma denominação social, inscrição no registro público, dever de lealdade no exercício da titularidade do capital social, responsabilidade na cessão da titularidade do capital social, outorga da função de administrador a terceiro, direito de físcalização dos livros, documentos e atos, vedação de ato do titular do capital conflituoso com o interesse da pessoa jurídica.

\section{Referências}

ABRÃO, Carlos Henrique. Empresa individual de responsabilidade limitada. São Paulo: Atlas, 2012.

ASCARELLI, Tullio. Problemas das sociedades anônimas e direito comparado. São Paulo: Saraiva, 1969.

BLOOM, Paul N.; KOTLER, Philip. Marketing para serviços profissionais. São Paulo: Atlas, 1990. 
BRASIL. Lei n. 5.172, de 25 de outubro de 1966. Dispõe sobre o Sistema Tributário Nacional e institui normas gerais de direito tributário aplicáveis à União, Estados e Municípios. Disponível em: <http://www. planalto.gov.br/ccivil_03/Leis/L5172.htm>. Acesso em: 14 set. 2012.

BRASIL, Lei n. 10.406, de 10 de janeiro de 2002, artigo 1.052. Institui o Código Civil. Disponível em: <http://www.planalto.gov.br/ccivil_03/ Leis/2002/L10406.htm>. Acesso em: 10 set. 2012.

BRASIL. Ministério da Ciência, Tecnologia e Inovação. Chamada Pública MCTI/SETEC/CNPq n. 17/12 - RHAE Pesquisador na Empresa. [2012]. Disponível em: <http://cnpq.br/en/web/guest/ chamadas-publicas;jsessionid=0F436C38963FE9483A8A8FFD6B 2CDD2C?p_p_id=resultadosportlet_WAR_resultadoscnpqportlet INSTANCE_0ZaM\&p_p_lifecycle $=0 \& p \_p \_s t a t e=$ normal $\& p \_p$ $\operatorname{mode}=$ view $\& p \_p \_c o l \_i d=$ column $-4 \& p \_p \_c o l \_p o s=1 \& p \_p \_c o l \_c o u n t=5$ $\&$ filtro $=$ abertas $\&$ detalha $=$ chamadaDivulgada\&desc $=$ chamadas $\&$ idDivulg acao=1241>. Acesso em: 26 nov. 2012.

BRASIL. Supremo Tribunal Federal. ADI n. 3.026-4/DF. Relator: ministro Eros Grau. Julgamento em: 23 de fevereiro de 2005. Disponível em: <http://redir.stf.jus.br/paginadorpub/paginador. jsp?docTP=AC\&docID=363283>. Acesso em: 14 set. 2012.

BORBA, José Edwaldo Tavares. Direito societário. Rio de Janeiro: Renovar, 2003.

CANOTILHO, José Joaquim Gomes. Direito constitucional. 5. ed. Totalmente refundida e aumentada. Coimbra: Almedina, 1991.

COMPARATO, Fabio Konder. Poder de controle na sociedade anônima. Rio de Janeiro: Forense, 1983.

FACCHIM, Tatiane. A Sociedade unipessoal como forma organizativa da micro e pequena empresa. 2010. Dissertação (Mestrado em Direito). Faculdade de Direito da Universidade de São Paulo, 2010.

FERRAGUT, Maria Rita. Responsabilidade Tributária: conceitos fundamentais. In: FERRAGUT, Maria Rita; NEDER, Marcus Vinícius. Responsabilidade tributária. São Paulo: Dialética, 2007. 
GRAU, Eros Roberto. A ordem econômica na Constituição de 1988: interpretação e crítica. 12. ed. Revista e aumentada. São Paulo: Malheiros, 2007.

. Direito, conceitos e normas jurídicas. São Paulo: Revista dos Tribunais, 1988.

KELSEN, Hans. Teoria pura do direito. Coimbra: A. Amado, 1984.

LUMIA, Giuseppe. Elementos de teoria e ideologia do direito. São Paulo: Martins Fontes, 2003.

MACHADO, Sylvio Marcondes. Limitação da responsabilidade do comerciante individual. São Paulo: Max Limonad, 1956.

. Questões de direito mercantil. São Paulo, Saraiva, 1977.

MORAES, Guilherme Duque Estrada de. Sociedade limitada e a nova lei, Gazeta Mercantil, São Paulo, 30 de junho de 2003, no caderno "Legal e Jurisprudência”. (página 1)

PUGLIESI, Fabio. Contribuição ao estudo do controle de preços. São Paulo, Dissertação (Mestrado em Direito): Faculdade de Direito da Universidade de São Paulo, 1993.

REQUIÃO, Rubens. A Preservação da sociedade comercial pela exclusão do sócio. Tese (apresentada para o concurso à cátedra de Direito Comercial na Universidade do Paraná). Universidade do Paraná, Curitiba, 1959.

. Curso de direito comercial. São Paulo, Saraiva, 2005.

SALOMÃO FILHO, Calixto. O Novo direito societário. São Paulo, Malheiros, 2002.

SERSON, Nilton. EIRELI e a subsidiária integral. Revista do Advogado, Associação dos Advogados de São Paulo, SP, n. 116, p. 146151, 2012.

WEBER, Max. O Direito na economia e na sociedade. São Paulo: Ícone, 2011. 
Fábio Pugliesi é Doutor em Direito pela Universidade Federal de Santa Catarina (UFSC), Mestre em Direito pela Universidade de São Paulo (USP) e Especialista em Administração pela Fundação Getúlio Vargas. Professor adjunto da Escola Superior de Administração e Gerência da Universidade do Estado de Santa Catarina (UDESC), do Centro Universitário para o Desenvolvimento do Alto Vale do Itajaí (UNIDAVI) e do Centro Universitário Estácio de Sá de Santa Catarina. E-mail: pugliesif@gmail.com.

Endereço profissional: Centro Universitário para o Desenvolvimento do Alto Vale do Itajaí. Rua Dr. Guilherme Gemballa, 13 - Caixa Postal 193. CEP: 89160932. Jardim América, Rio do Sul/SC.

Daniel Mayerle é Mestre em Direito pela Universidade do Vale do Itajaí (UNIVALI) e professor do Centro Universitário para o Desenvolvimento do Alto Vale do Itajaí (UNIDAVI).E-mail: mayerle@unidavi.edu.br.

Endereço profissional: Centro Universitário para o Desenvolvimento do Alto Vale do Itajaí. Rua Dr. Guilherme Gemballa, 13 - Caixa Postal 193. CEP: 89160932. Jardim América, Rio do Sul/SC.

Andrey Ricardo Machado é Acadêmico de Direito do Centro Universitário para o Desenvolvimento do Alto Vale do Itajaí (UNIDAVI). E-mail: andrey_ricardo_ monteiro@hotmail.com.

Endereço profissional: Centro Universitário para o Desenvolvimento do Alto Vale do Itajaí. Rua Dr. Guilherme Gemballa, 13 - Caixa Postal 193. CEP: 89160932. Jardim América, Rio do Sul/SC. 